\title{
Translation of French Commentaries From the Aspect of Functional Translation Theory-Taking Jingjiang Seignior's Tomb in Guilin as an example

\author{
Qiongfang Qin
}

Department of Tourism Foreign Languages, Guilin Institute of Tourism, Guilin, 541006, China

Keywords: functional translation theory; French commentaries translation; Jingjiang Seignior's Tomb

\begin{abstract}
As an international tourism resort, Guilin is always a preferred choice for French tourists. They not just greatly admire the beautiful landscapes in Guilin, but also speak highly of the historical cultural relics here. The Jingjiang Seignior's Tomb in the suburb of Guilin is not just the representative of seignior culture in Ming Dynasty, but also one of the tour itineraries preferred by French tourists. In this paper, Guilin Jingjiang Seignior's Tomb is taken as an example to explore the translation methods and skills aiming at cultural communication and exchanges during French guides based on the functionalist translation theory.
\end{abstract}

\section{Introduction}

More and more foreign tourists are attracted by the mysterious and ancient oriental culture. They come to China regardless of the long distances. Because of the cultural differences between east and west, some cultural meanings can not be understood well by foreign tourists. Especially, when foreign tourists are visiting tomb architectures, the differences between the cultural connotations and the guide commentaries make them puzzled.

In this paper, Guilin Jingjiang Seignior's Tomb is taken as an example. It is an emperor's tomb established in Ming Dynasty, which is located on the southwest foot of Yaoshan Mountain at the eastern suburb of Guilin. It is called as the "First Tomb in the South of the Five Ridges". After hundreds of years, there are only a few survive from the 11 tombs of the 12 Jingjiang Kings. Moreover, grave robbery was very serious. Therefore, most of the tomb constructions were destroyed. What we called as Jingjiang Seignior's Tomb is a shared tomb of the third Jingjiang King Zhu Zuojing and his wife Shen. It is not a natural scenic sport. Tourists can understand the seignior tomb culture only with detailed explanations. For French guides, when translating the guide commentaries, they should take many factors into consideration, such as, the education level of the tourists, their tourist demands, appreciation level and aesthetic level, etc. The differences in these aspects make translation and interpretation become difficult. Sometimes, French guides' explanations for the cultures are not accurate, which may cause misunderstanding in cultures. Therefore, functionalist translation theory and some other methods and skills are adopted in this paper with the hope to explore the translation of the French commentaries of the scenic spot.

What is functionalist translation theory? In 1970s, functionalist translation theory sprang up. The leading figures in this field contain K·Reiss, HJ·Vermeer, Nord and $\mathrm{JH} \cdot M a n t t a r i$, etc. Reiss·K divided texts according to functions. He combined the function of language with translation to put forward "the particularity of translation" should be treated as a new model of translation criticism. Then, HJ-Vermeer and C. Nord et. al put forward the "skopos theory", which is the core theory of functional translation theory. "Translation methods and strategies are determined by the purpose and function of the target language” and the source language is only a source of information. During translation, translators should focus on the new communication environment of the target language and the demands of targeted readers rather than those of the source language, so as to realize the expected communication function in the targeted context. During practical translations, many translators find that different translation strategies should be taken under different conditions. Coincidently, functional translation theory provides theoretical references for some translational actions that are effective but not in line with the previous translation standards. The appearance of this translation theory changed the situation of focusing on linguistics to emphasizing functions and social and cultural factors. 
Guide translation behavior is a process of spreading information, which is a kind of intercultural communication with a certain purpose. The objective of tourist translation is to introduce scenic spots to foreign tourists accurately, so that they can understand and appreciate the scenic spots. As a result, the final goal of disseminating culture can be realized. Britain contemporary translation theorist Newmark put forward that different translation strategies should be applied for different text styles. Tourist publicity materials are information-based and guidance-based materials. Therefore, communicative translation method should be adopted and the understanding and response of readers should be emphasized. The expressions, forms and words should be in line with the habits of targeted language. ${ }^{[1](1988: 50-51)}$

\section{Exploration for the translation strategies for the French commentaries of Jingjiang Seignior's Tomb}

\section{Complementary translation}

Complementary translation is a widely used method in tourism translation, which is also an effective translation method. It refers to make positive complements for the structure or meaning of the targeted language according to the demand of the translation goal. Complementary translation is widely used in the translation of proper nouns (names of persons or places). In this way, the meaning can be clarified. For instance, when French tourists come to Guilin for the first time, it is better for guides to translate "Guilin" as Guilin, une forêt d'osmanthus. In this way, not only the destination Guilin is pointed out, but also the feature of the city, osmanthus forest, is highlighted. Therefore, at the beginning of the tourism, tourists are long for the beautiful city. The function of tourism translation is realized. However, if "Guilin" is translated as "Guilin" directly at the first time, the simple name may be forgotten by French tourists at any time. Therefore, when the meaning of placename is expressed with complementary translation, tourists can have a deeper understanding for the place. Meanwhile, complementary translation can be adopted to translate “Jingjiang Seignior's Tomb".

Example 1:

$\mathrm{A} \backslash$ Les tombeaux royaux de Jingjiang

$\mathrm{B} \backslash \mathrm{L}$ ' édification des tombeaux royaux de Jingjiang

ClLes tombeaux royaux de Jingjiang, roi héréditaire de cette région sous la dynastie des Ming

$A$ is the generally scenic spot name translation, which is the combination of paraphrase and transliteration. Some guides may use B: L' édification des tombeaux royaux de Jingjiang during introduction. When the complementary translation is used, the head noun is changed from tombeaux to L' édification. In sentence B, it is good to add the word L' édification (architecture), because the scenic spot is a tomb architecture. The emphasis is the L' édification (architecture) but not the tombeaux (tomb, precious city or grave mound). As for $\mathrm{C}$, complementary translation is also used. Appositive is adopted to explain the "Jingjiang (King)" is the hereditary (seignior) king in that place during Ming Dynasty. It can also play the role of explanation. As a result, tourists can compare the Guilin Jingjiang Seignior's Tomb with the Beijing Ming tombs they visited before. Therefore, they can find out the difference --- emperor and seignior.

Applying complementary translation to translate the names of Chinese figures and places can pass more information to foreign tourists, so that they can understand the connotation and the cultural meanings of the Chinese names.

Example 2:

Parmi les animaux fantastiques qui décorent la voie des Esprits, vous retrouverez quelques-uns des neuf fils du dragon. C'est le symbole de l'empereur, souverain de toutes les créatures selon la tradition populaire et on l'a aussi doté de neuf fils, qui ont des apparences différentes.

Complementary translation can be used to explain some habitual cultural phenomena in china. In Chinese traditional culture, dragon is a symbol of power. Imperial families in the feudal age used to compare themselves to the sons or grandsons of dragon. However, dragon is not a propitious animal. In the above translation, a complementary is given that dragon means the imperial power, which rules all lives. Therefore, foreign tourists will not fell puzzled when they see the son of dragon among the stone figures. Moreover, they can have a better understanding in the power hierarchy in the Chinese feudal age. 


\section{Omission}

In the Chinese tourist information, Chinese love to quote the words of famous people, ancient poems and classical Chinese from literatures to strengthen the image sense. The translation of these documents is relatively difficult. If French tourists don't have the equal cultural background and similar aesthetic appreciation, the translation many be difficult to the tourists. Therefore, omission should be used in these kinds of translation to ensure the spreading of the basic information.

Example 3:

Les cruentés de Zhushouqian avivent le mécontentement des habitants.

"Base person" and "behave badly" are the description related to Zhu Shouqian. One of the difficulties in classical Chinese translation is to express the rhythm, image and artistic conception of the source language. If it is badly translated, it will be meaningful. From the aspect of the Skopos Theory of functional translation theory, omission can be used to avoid the difficult and realize the same expression effect. For instance, "Les cruentés" (cruel) is used to express "base person" and "behave badly". It is simple but clear. Moreover, it is more suitable for the expression habit of French.

For another example:

Example 4:

Deux mandarins se présentent avec leur tablette honorifique devant l'empereur.

Omission is adopted in the translation of this sentence. The literal meaning of the target language is that two civilian officials stand before the king with Wu. The "Wu" in the source language is translated to leur tablette honorifique (honorary board) rather than leur tablette à la main "hand plate" to avoid misunderstanding for historical cultural knowledge caused by literal translation. In the target language, the "with $\mathrm{Wu}$ in their hands" doesn't directly modify "official civilians". Instead, it becomes the predicate verb and object of the sentence. Combining with the gesture of the figures "standing with $\mathrm{Wu}$ in their hands", the worship of officials at the morning report is shown completely. Although the literal meaning of $\mathrm{Wu}$ is not translated, noun phrases are used to make sentence. As a result, the language information in the source language is maintained to convey correct information. Therefore, the goal of translation is realized.

\section{Adaptation}

C.Nord pointed out in the book Text Analysis in Translation that it is a part of the daily work of each professional translator to adjust and rewrite the source language according to the cultural standards of the target language. From the aspect of methodology, we can distinguish translation (micro) from rewriting. However, I doubt the function. I do prefer to conclude rewriting in translation, so that people (translation users and promoters) can understand it. ${ }^{[2](1991: 39)}$

Adatptation is called as "flexible" translation. Based on the correct information of the source language, adaptation can enrich the colors of the language and activate the meaning of the sentence when the cultural context can be changed.

Example 5:

Le tombeau qu'on va découvrir est celui de Zhuangjianwang et sa concubine, troisième génération des rois de Jingjiang.

"Visit" should be "visiter" in French. However, this word is frequently used in French tourism translation. During practical translation, it can be translated to découvrir, which means reveal, open and discover, to express the meaning of exploration. Therefore, the French tourists may be interested in the tourism, because it is not just a common visit but an exploration for Chinese culture. Therefore, adaptation is not "freewheeling". It should be mastered well to realize the effect of translation, or otherwise it will become "mistranslation".

Example 6:

Au début de la dynastie des Ming, pour renforcer le despotisme centralisé, l'empereur Zhuyuanzhang, fondateur des Ming, confère les fiefs à ses 24 fils et 1 petit-fils de son frère dans quatre coins du pays. Parmi eux, en 1370, le fils de son neveu est fieffé sous le titre de roi de Jingjiang de cette région.

As for the translation of "Ming Emperor Zhu Yuanzhang", transliteration "Mingtaizu" is not adopted so does the paraphrase "Le premier empereur de la dynastie des Ming (the first emperor in Ming Dynasty)". Instead, the expression "l'empereur Zhuyuanzhang, fondateur des Ming" is adopted. The structure combining noun and appositive is adopted to explain the status of Zhu 
Yuanzhang, the first emperor in Ming Dynasty. Therefore, this kind of translation is more suitable than the two previous ones. In the source language, "one of his brother's grandsons" and "his brother's grandson" is the same person. In the target language "petit-fils de son frère" and "le fils de son neveu" are used to avoid repetition.

\section{Analogy}

When people are curious about the unknown and strange things, they want to explore. If analogy can be used to infer the nature and properties of the unknown matters, the goal of cognition can be realized soon. For instance, when introducing the time when Zhuyuanzhang established the Ming Dynasty, the western Renaissance can be mentioned to enable French tourists have a better understanding in Chinese history, so that they can accept the time easily. Moreover, the visited scenic spots can be compared with the current spot. For instance, the Beijing Ming Tombs can be compared with the Guilin Jingjiang Seignior's Tomb. During the visit, analogy can be adopted to translate the name "Jinshui Bridge".

Example 7:

Pour la deuxième cour, la voie des Esprits est coupée en deux sections par un pont en jade de pierre, version miniature de celui de la Cité interdite de Beijing. C'est le pont de l'eau d'or, appelé aussi le pont de la ceinture de jade.

In the target language, the bridge in the Jingjiang Seignior's Tomb scenic spot can be compared with the "Jinshui Bridge" that tourists have visited in the Imperial Palace of Beijing. The guide should explain that this bridge is a scaled-down version of the "Jinshui Bridge" in the Imperial Palace of Beijing. Therefore those two bridges can be associated to strengthen the impression of the tourists and realize the information function of the tour commentary.

\section{Conclusion :}

Guilin Jingjiang Seignior's Tomb scenic spot is not just a human landscape favored by many French tourists, but also one of the topics that must be examined in the national tour guide oral test in the Guangxi Region. Because the tour commentary for the scenic spot covers every aspect of history, architecture, customs and folk cultures, etc., it is very difficult to translate. Therefore, some translation strategies and skills in functional translation theory should be adopted to realize the goal of spreading cultural information.

As Nord thought that goal determines manners. Translators can determine the specific tranlation strategies and manners according to the specific target language context by combining the socal background, expectation and social knowledge and communication demands of the readers. The communication function of targest language should not be limited by the from of source language. ${ }^{[7]}$ (2004:47)

\section{References:}

[1]Newmark. A Text book of Translation [M]. New York: Prentice Hall, 1988.

[2]Christiane Nord. Text Analysis in Translation[M]. Shanghai: Shanghai Foreign Language Education Press, 1991.

[3]Isabelle Jeuge-Maynart. Chine de Pékin à Hong Kong [M]. Paris: Hachette Livre, 1998.

[4] Chen Gang, Cross-cultural Awareness --- An Essential Characteristic of Commentaries Translators [J], Chinese Translators Journal, 2002, (2).

[5] Chen Xiaowei, Enlightenment of Functional Translation Theory [J], Chinese Translators Journal, 2002, (4).

[6] Huang Jiacheng and Zeng Youyun, Guilin Tourism [M], Guilin: Lijiang Press, 1998.

[7] Jia Wenbo, Applications of Functional Translation Theory [M], Beijing: China Translation and Publishing Corporation, 2004. 